\title{
La videopolítica, \\ los videoescándalos \\ y la sucesión presidencial en México
}

JAVIER ESTEINOU MADRID

\section{Las tecnologías de la información y la transformación del Estado contemporáneo}

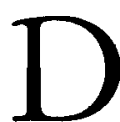
ebido a las nuevas capacidades tecnológicas que, a principios del siglo $\mathrm{XXI}$, conquistaron los medios de información colectivos, especialmente los electrónicos, éstos incrementaron sustantivamente su eficacia de transmisión informativa y de persuasión colectiva, y se convirtieron en el centro del poder ideológico y político contemporáneo de nuestra nación. En ese sentido, de haber sido instrumentos de difusión relevantes en 1960 en México, de transformarse en instituciones importantes de socialización en 1970 y de convertirse en el cuarto poder político a partir de 1980, desde principios de 2000 se transformaron en el vértice del poder actual. Es decir, ya no sólo son simples instituciones importantes de información o el cuarto poder, sino que ahora se han convertido en el "Primer Poder" ideológico que existe en nuestra sociedad.

Con la conquista de esas propiedades, los medios de información se han convertido en las extensiones del hombre y de las instituciones, y en consecuencia han construido una nueva zona de acción social: el espacio virtual. En este sentido, la emergencia de los medios de comunicación y de las nuevas tecnologías de información en México, no sólo representó la maduración del modelo de la Sociedad de la Información y la radical transformación de las superestructuras culturales de nuestras comunidades; sino que básicamente, el fenómeno más relevante que produjo fue la expansión intensiva de la dimensión ideológica de la sociedad mexicana a una esfera más amplia y versátil. Esto es, en términos generales, con la

- Universidad Autónoma Metropolitana, Unidad Xochimilco. Correo electrónico: jesteinou@prodigy.net.mx 
presencia de los canales de difusión, la sociedad mexicana en su conjunto sufrió un gran aumento en el aspecto cultural, desde el momento en el que las instituciones, los grupos o los individuos pudieron extender a distancia la realización de sus tareas o funciones específicas tradicionales, a través de las tecnologías de información y comunicación. ${ }^{1}$

De ese modo, el espacio público —entendido como el territorio libre, abierto y autónomo donde participan los individuos, los grupos y las instituciones según sus intereses y necesidades-, se transformó sustancialmente con la existencia de los medios de información originando nuevas esferas públicas, según fueron las características y el impacto social que produjo cada nueva tecnología de comunicación que emergió en nuestro territorio. En este espacio público se dan acciones privadas y acciones públicas. Las acciones privadas responden a intereses particulares, la mayor parte de las veces mercantiles y no están abiertas a todos los sectores. Las acciones públicas son colectivas y están abiertas a todos los sectores para discutir las realidades y los problemas de conjunto. En ese sentido, la revolución tecnológica de los medios de información los convirtió en las herramientas básicas para construir lo público y actuar sobre la cosa pública.

De esa manera, con la introducción de las innovaciones tecnológicocomunicativas, se generaron en el país nuevos espacios colectivos, públicos y privados, dedicados a la economía, la política, la gobernabilidad, los servicios, la educación, la religión, la salud, el comercio, la cultura, el entretenimiento, los deportes, la fantasía, el amor, etcétera. Así, la sociedad mexicana entró en la fase de producir nuevos procesos culturales de consecuencias sociales amplificadas e insospechadas.

Es por ello que, con la presencia de los medios de comunicación lo que se transformó en nuestra República, a corto plazo, fue el esqueleto ideológico de la sociedad en su conjunto y a largo plazo, el del Estado mexicano. Dicho espacio se convirtió en una nueva franja de interacción social donde se produjeron fenómenos de ampliación y extensión de las personas, los grupos, las instituciones y del Estado dando origen en México a la Sociedad Extensa. De esta manera, con la ampliación de la Sociedad Extensa, vía la acción de las tecnologías de información, el Estado experimentó una gran transformación al interior de su estructura y dinámica económica, política, social y cultural, pues las tareas de construcción, dirección y cohesión ideológica que realiza, entraron en una

1 Una concepción intuitiva, pero también idealista sobre la forma como la sociedad se modifica con la presencia de las tecnologías informativas, la encontramos de manera embrionaria en el pensamiento de Marshall McLuhan (1979). Una crítica moderada al pensamiento de McLuhan puede consultarse en Gianpiero Gauraleri (1981).

Para un panorama general sobre la línea de evolución que han seguido las tecnologías de información desde el telégrafo en 1840 hasta la comercialización de los cristales de silicio, véase Sean McBride (1985: 31-36). 
nueva fase de extensión geométrica que dio origen a una nueva faceta del poder: el moderno Estado Ampliado. ${ }^{2}$

Debido a ello, es muy importante subrayar que cuando se habla de medios, no se está hablando de simples acciones de esparcimiento, información, actualización o diversión; sino que, en última instancia, se habla de la transformación del espacio público y, en consecuencia, de la construcción de la estructura del Estado Ampliado y de la Sociedad Extensa, vía la expansión del espacio virtual.

De esta forma se creó, cada vez más, una sociedad mediática que produjo una nueva atmósfera cultural colectiva de naturaleza virtual o comunicósfera que ocasionó que el conjunto de las principales instituciones de gobernabilidad ahora funcionen a distancia por intermediación de los canales de información, especialmente electrónicos y las nuevas tecnologías de información. En este sentido, la casi totalidad de las instituciones tradicionales como son la escuela, los partidos políticos, el Congreso, la Iglesia, las secretarias de Estado, las empresas, los órganos de gobierno, los movimientos sociales, las dinámicas comunitarias, etcétera, buscan proyectarse y ampliarse vía los medios de información, asumiendo las reglas mediáticas que imponen éstos, ya que lo que no aparece en los medios muy difícilmente existe en la conciencia colectiva: los medios electrónicos se convirtieron en el epicentro cultural, ideológico y espiritual de la sociedad mexicana de principios del nuevo milenio.

La expansión de esta realidad mediática modificó la estructura, dinámica y las fronteras del Estado mexicano y de la cultura nacional creando un nuevo tejido en la esfera del poder que generó al Estado Mexicano Ampliado. De esta forma surgió el Estado mediático que se caracteriza por ejecutar sus tradicionales funciones de dirección, educación $y$ gobernabilidad, vía los medios de información como brazos o prótesis de expansión de su capacidades de orden, administración, educación y de dirección. Así, observamos el surgimiento de nuevas políticas de difusión que dieron origen a la teleadministración pública, el teledeporte, la teleeducación, la telebanca, la teleoración, la telemedicina, la televenta, la telediversión, la telepolítica, la teleguerra, la radio asistencia psíquico-

${ }^{2}$ El concepto de Estado Ampliado es una categoria analítica totalmente abandonada por la reflexión crítica de la comunicación europea y latinoamericana. La única disciplina que la ha retomado y desarrollado ha sido la Ciencia Política a través de la teoría de los aparatos de hegemonia, representada, especialmente, por los brillantes trabajos de Christine BuciGlucksmann.

Nuestro esfuerzo consiste en recuperar dicho arsenal teórico olvidado para enriquecerlo y expandirlo con las aportaciones que ha ofrecido la evolución material de los medios de comunicación y de las tecnologías de información sobre la trama de los aparatos de hegemonía tradicionales. Estamos convencidos de que esta matriz teórica es una de las principales vetas y directrices conceptuales que nos permiten comprender las funciones y transformaciones que ejercen las tecnologías de comunicación dentro del actual ámbito del poder. 
emocional, la radio orientación vial, la radio iglesia, la radio orientación sexual, etcétera.

\section{Los medios y la modificación del espacio público}

Con la existencia del nuevo espacio virtual se modificaron las reglas y dinámicas tradicionales con las que nuestra sociedad antaño se articulaba, organizaba y participaba colectivamente. En ese sentido, se produjo un profundo cambio en la jerarquía de poderes que conforman el esqueleto del poder y de la movilización cotidiana de nuestra sociedad donde los medios de información ahora son el centro del poder político, cultural, mental y espiritual cotidiano de nuestra República: los medios se transformaron en la nueva plaza pública y en los grandes cerebros colectivos que dirigen a la sociedad.

Por lo tanto, ya no ha sido el discurso político ni la acción de los representantes populares y ni siquiera la prensa tradicional lo que ha permitido a los mexicanos tener una visión cotidiana de sí mismos y del futuro de la nación. En la actualidad, son las redes de televisoras y radiodifusoras, quienes acceden permanentemente a la mente de los mexicanos y les informan o les deseducan sobre la conducta a seguir en la sociedad contemporánea que les corresponde vivir (Labra, 1989: 7).

De esta manera, los espacios cotidianos de relación simbólica que permanentemente producen los aparatos cotidianos de comunicación entre emisores y colectividades son la principal arena social donde diariamente se construye o destruye, mental y afectivamente, a la sociedad mexicana y al Estado. Por consiguiente, podemos afirmar cada vez más que en la sociedad mexicana de 2000 , las batallas políticas o sociales se ganan o pierden en los medios de comunicación colectivos y no en otras áreas de las contiendas sociales. Con ello, a principios del tercer milenio la hegemonía social, es decir, el principal trabajo masivo de convencimiento, asentimiento $y$ dirección social, se logra pacíficamente vía los medios de comunicación colectiva y no mediante otros aparatos ideológicos de la gobernabilidad. Los medios y su producción simbólico-cultural, se convirtieron en el principal cemento eficiente que articula o desarticula cotidianamente a los grupos sociales.

En la actualidad debemos tener presente que en nuestro país, frente a la tradicional acción del sistema escolar y religioso, los medios se han convertido en la principal red cultural y educativa capaz de cambiar, con mayor rapidez y agilidad, las cosmovisiones, los valores, las actitudes, los hábitos y las conductas de los receptores. En otras palabras, dirigen la cultura cotidiana en cada periodo histórico y social, es decir, los medios se han transformado en los principales mediadores culturales, a través de los cuales se articula ideológicamente a nuestra sociedad, convirtiéndose 
en las principales instituciones organizadoras colectivas de la historia y la vida moderna de México.

De esta forma, no obstante que los medios de difusión no son instituciones omnipotentes para producir efectos automáticos sobre los auditorios, gracias a las evolucionadas capacidades materiales que han alcanzado poseen suficientes habilidades tecno-ideológicas efectivas, históricamente ya comprobadas, para crear y cambiar las formas de pensar y actuar, y para imprimir fuertes direcciones sociales a los campos de conciencia de los mexicanos: su principal poder es virtual y mediático y de aquí se derivan otras influencias económicas, políticas, mentales y espirituales sobre la sociedad. Dichas tendencias se generan a través de la práctica de la agenda setting, que es la capacidad informativa y pedagógica que despliegan los medios de información para centrar cotidianamente la atención de los diversos públicos en sólo algunas realidades y no en otras, vía sus políticas de información o de programación. Con ello, de forma silenciosa, permanentemente construyen una jerarquía del conocimiento de la realidad, de los valores, de la política, de la cultura, de la historia y de la vida que se convierte en un marco fundamental de referencia y de acción que articula a los ciudadanos. Así, la agenda setting se ha transformado en una de las principales herramientas comunicativas para construir diariamente la hegemonía social en México.

En este sentido, la construcción o destrucción de la realidad masiva cotidiana, es decir, de lo que existe o no existe, de lo que es bueno o es malo, de lo que hay que recordar o hay que olvidar, de lo que es importante o no, de lo que es verdad o es mentira, de lo que es visible o invisible, de lo que son valores o antivalores, de lo que es la opinión pública o de lo que no es, de lo que es virtuoso o no, de lo que hay que hablar o hay que silenciar, de lo que hay que admirar o rechazar, de lo que es el éxito o el fracaso, etc., se elabora, cada vez más, especialmente en las grandes ciudades, desde los medios colectivos de difusión.

\section{Comunicación colectiva y ampliación de la política}

Con la concentración de los fenómenos de cultura de masas, vía los medios de información, surgió en nuestra sociedad el fenómeno de la telepolítica como una nueva realidad mediática que transformó las reglas tradicionales de los procesos políticos y electorales e introdujo otras nuevas realidades simbólicas que ponen el acento en la forma del quehacer político y no en el contenido de las propuestas. De esta manera, aparecieron los teledebates, el sbow político, la construcción de la "plaza pública electrónica", el desarrollo del marketing político, la actuación histriónica de los candidatos, el sensacionalismo político, la sobreexposición de los candidatos en los me- 
dios, la búsqueda partidista del raiting, etcétera, que crearon nuevas condiciones que determinan el éxito electoral.

De ese modo, se transformó la plaza en videoplaza, la política en videopolítica, la denuncia en videodenuncia, la promoción política en videodestape, ${ }^{3}$ los mítines en videomitines, la marcha en videomarcha, el gobierno en telecracia, y la democracia en videodemocracia.

Así, en nuestra época moderna constatamos que, por ejemplo, en la política el detonante central que dispara la decisión ciudadana para definir la dirección de su voto, se desplazó del espacio que ejercía la labor de contacto directo con las masas, para ahora trasladarse drásticamente al campo de los medios de comunicación colectivos y sus derivados de cultura de masas, es decir, en el México de finales del siglo xx la hegemonía política del país ya no se construye a través del mitin tradicional y de sus instrumentos colaterales de antaño, sino que ahora la hegemonía se conquista, predominantemente, a través de la actividad de persuasión civil 344 a distancia que los partidos políticos efectúan vía los medios de comunicación, en especial, los modernos canales electrónicos.

Dicha mutación social significa para las nuevas elecciones que el espacio estratégico donde se dará y decidirá la batalla por el convencimiento de las masas nacionales, ya no serán los kioscos comunitarios, los ateneos, los recintos de las casas de cultura, las alcaldías, los auditorios cerrados, las alamedas de las colonias, las visitas domiciliarias, las explanadas universitarias, las pintas de las bardas, etcétera. Donde se reúnen los candidatos con sus distintos públicos; sino que, sin desaparecer esas actividades, el nuevo espacio neurálgico donde se definirá la elección civil será la zona de mediación política que construyen los medios de comunicación colectivos entre partidos y sociedad, vía la dinámica simbólica que éstos producen.

Con ello, el modelo de comunicación de los medios atravesó la estructura, procesos y operación práctica de todas las instituciones sociales básicas para la dirección del país. Este fenómeno se realiza de formas diferenciadas según los momentos de equilibrio o crisis por los que atraviesa la evolución del sistema social.

Durante los periodos de equilibrio social, los medios ocupan un lugar central de prolongación mediática de las instituciones tradicionales y de contrapeso político-ideológico de los poderes formales establecidos, como son el Congreso, los partidos políticos, las iglesias, el ejército, etcétera. En

${ }^{3}$ El primer destape político en México por televisión se hizo con el lanzamiento a la presidencia de la República del candidato independiente Jorge Castañeda, cuando el 25 de marzo de 2004, en el marco de los videoescándalos, presentó su candidatura a través de spots televisivos que convocaban a los "sin partido" a derrotar la partidocracia impuesta por el PRI, PAN y PRD. "Formaliza Castañeda precandidatura al 2006", en Reforma, 26 de marzo del 2004, p. 9-A; "Minipartidos a la caza del güero", en Revista Milenio, 23 de febrero de 2004 , p. 15. 
esta fase, las diversas instituciones tradicionales absorben las caracteristicas del lenguaje, los formatos, los géneros, la gramática, los códigos, la concepción, la velocidad, la persuasión, las formas, las estrategias, la dinámica, las ideologías, etc., del modelo de información mediático que se impone sobre los otros modelos de comunicación convencionales de las instituciones y de los grupos tradicionales establecidos. Las instituciones emplean a los medios para prolongarse vía éstos y ejercer sus funciones y tareas específicas.

En cambio, en los periodos de crisis o transición social, además de continuar la existencia de los fenómenos anteriores, los medios penetran las instituciones sociales a tal grado que sustituyen o reubican a los órganos de administración social mas débiles o que están en crisis de funcionamiento y legitimación. Así, por ejemplo, ante la caída de las propuestas ideológicas de las iglesias y de las religiones para darle sentido y esperanza a la vida de los hombres del siglo xxi, la televisión las sustituye aceleradamente con la nueva fe mediática del reencantamiento mágico audiovisual de la vida.

Ante a la crisis del Congreso de la Unión, los medios lo suplantan con nuevos líderes mediáticos y sus procesos de representación política. La torpeza de los políticos de no aprovechar los canales de difusión para extender o ampliar su deber, comparecen ante los medios como súbditos cotidianos inclinados ante el espejo deformado que ellos mismos crearon (Caballero, 2004: 36). La descomposición y baja de credibilidad de la población en los partidos políticos, los medios los superan con nuevas formas de organización y dirección social. El decaimiento de la política como dinámica de discusión y resolución de los grandes problemas sociales, los medios la sustituyen con estrategias de información amarillistas y sensacionalistas. La debilidad de actuación del sistema de justicia, los medios se convierten en el Poder Judicial Mediático y lo desplazan con los juicios electrónicos paralelos. La deficiencia de los procesos de representación electoral, los medios se autocolocan como la representación mediática de la población, e incluso respaldan su nuevo lugar de portavoz colectivo con la votación electrónica virtual. La ineficacia de la diplomacia, los medios se posicionan como el territorio para dirimir o incrementar los conflictos sociales. La descomposición de la administración pública, especialmente por la corrupción, los medios la reubican con el gobierno electrónico "eficiente", "aséptico" e "incontaminable". La incapacidad de gobernabilidad de los órganos de gobierno, los medios la sustituyen con la gerencia electrónica colectiva, transformando al pueblo de ciudadanos en espectadores y consumidores cautivos.

El debilitamiento de las redes de los diversos tejidos sociales, los medios construyen sus nuevos tejidos virtuales desde los cuales le dan un nuevo sentido y dirección inmediatista a los individuos. La caída de 
los líderes orgánicos, los medios crean sus caudillos electrónicos basados en la mercadotecnia. el descuido o desmembramiento de las organizaciones civiles, los medios convierten a los ciudadanos en auditorios cautivos que contemplan la versión privada de lo público que ellos construyen.

La incapacidad de respuesta del sistema educativo, los medios la remueven con la escuela audiovisual cotidiana que indica cómo vivir la vida. El deterioro del lenguaje, los medios lo reemplazan con los slogans o modismos del momento. El debilitamiento de la estructura de pensamiento racional, los medios la desplazan con la perspectiva hedonista, conductista y sensacionalista de ver la vida placenteramente. La debilidad de los aparatos culturales para construir identidades, los medios la compensan creando referentes imaginarios inmediatistas de existencias de muy corto plazo y de constante recambio simbólico. La debilidad del Estado para conservar la memoria histórica de la sociedad, a largo plazo, los medios la sustituyen con la formación de una memoria autista cuya capacidad máxima de recuerdo gira alrededor de la dinámica de la agenda setting. La decadencia de los valores tradicionales, los medios los suplantan por los nuevos valores de la cultura de masas moderna. En pocas palabras, la crisis de las instituciones del Estado y de la sociedad, la capacidad omnipresente y persuasiva de los medios construye nuevas credibilidades, sistemas simbólicos y hegemonías ideológicas basadas en estrategias de seducción de mercado y de hipno-tización social, cuyo termómetro de éxito es el raiting.

Frente a esa realidad, se puede decir, como escenario futuro, que a mayor desintegración y fragmentación de los poderes públicos tradicionales y consolidación de los poderes mediáticos cohesionados en sólidas estructuras monopólicas privadas, de mediano y largo plazo, el poder de los medios suplantará crecientemente el ejercicio de las funciones públicas fundamentales del Estado para regular los conflictos entre los actores sociales y éstas serán, progresivamente, ejercidas conforme a los intereses y planes de los mega consocios privados. Esta concentración de fuerza del mega poder mediático, los demás poderes menores o disminuidos le rinden tributo y aceptan la imposición de sus reglas y permiten que los primeros se posicionen como los nuevos administradores y usufructuarios de las principales tensiones, conflictos o contradicciones sociales de los otros poderes en el país (Scherer, 2004: 23). Así, los proyectos de persona, trabajo, desarrollo, cultura, ciudadanía, patria, nación, planeta, en pocas palabras de la vida, son diseñados y realizados cada vez más, a partir de los intereses y necesidades de lo privado y no desde los ejes de lo público colectivo.

De ese modo, los sistemas de comunicación mediáticos adquieren una gran autonomía sobre los poderes públicos y se transforman en el poder supremo, el poder del poder, que suplanta las funciones que le correspon- 
den al Estado. Así, ante el deterioro de la esfera priblica, de los partidos, del Congreso de la Unión, de la política, del Estado, del programa colectivo de crecimiento, de los valores, del proyecto de nación, etc., los medios de difusión se convirtieron en el primer gran poder político-ideológico cotidiano que seduce, reencanta y conduce, mental y afectivamente, a la sociedad mexicana. En ese sentido, "los grandes consorcios televisivos, cada vez más, substituyen a las instituciones tradicionales del papel protagónico en los procesos de socialización y de construcción de los espacios clave de la política" (Corral, 2003).

De esa manera, considerando que el ejercicio del poder social nunca desaparece, sino que sólo se reacomoda, desplaza o traslada, de un lugar a otro, según son las fuerzas o debilidades de los actores sociales para ejercerse de diversas maneras, encontramos que al desmantelarse en México el viejo modelo corporativo del Estado que construyó el PRI durante más de 70 años, se movieron las viejas estructuras de orden y control que existían para dar paso a la apertura social y a la transición política a la democracia. Así, al modificarse el acotamiento del tradicional poder unipersonal del poder Ejecutivo y ante la falta de respuesta del nuevo gobierno para sostener una firme política de conducción nacional eficiente, surgió una severa crisis institucional y de gobernabilidad que generó vacíos de poder que, gradualmente fueron ocupados por los medios de información para conducir a la sociedad. En ese sentido, "el poder comunicativo actualmente acompañado por las políticas del gobierno tiende a imponerse no sólo por encima de la voluntad de los demás sino, más grave aún, a imponer a la autoridad legítima una autoridad impune. Condiciona, impone, reglamenta, elimina impuestos, orienta y hasta informa a la sociedad acerca de las políticas de comunicación. Antes negociaban, hoy parecen estar por encima de ello, ya no lo requieren, se impone al poder del gobierno quien parece estar a su disposición. Anteriomente, las televisoras estaban al servicio del presidente, ahora el presidente está al servicio de las televisoras" (Corral, 2002). En otras palabras

el gran negocio de la televisión mexicana siempre estuvo sometido a los intereses políticos en turno, medrando a cambio de su servilismo. Hoy los papeles se han invertido y los concesionarios no sólo presionan y obtienen del poder político multimillonarias transferencias, sino que lo substituyen como poder fáctico. Es el poder mediático el que somete sin excepción, sin reglas, sin frenos, sin sanciones por sus excesos u omisiones. De paso, dueños y conductores de la televisión juzgan y exhiben a una clase política que obedece lógicas mediáticas, con las que aspira a salir bien librada para mantener la ilusión de que gobierna. ${ }^{4}$

4 “Todo el poder", Proceso, núm. 1433, México, 18 de abril del 2004, p. 7. 
Así, en la vida cotidiana, el poder mediático de los medios sustituye cada vez más a la política, y éstos se transforman en los representantes de la voz y la opinión de la sociedad, cuya tutela se confirma diariamente con la aplicación de las encuestas de opinión que realizan y que han dado origen a la sondeocracia electrónica que cotidianamente se promueve de manera intensiva como la nueva forma de participación, representación y democracia colectiva. Con esta intervención mediática el proyecto autorregulatorio de las industrias culturales formula que ya no es necesario el Estado regulador y la transición política a la democracia, pues la nueva regulación y la democracia se alcanza con la participación espontánea y representativa en el espacio virtual.

\section{Los videoescándalos y la sucesión presidencial de 2006}

La existencia de la videopolítica en México se confirmó de manera espectacular a principios de 2004 cuando ante la profunda crisis de legitimidad y honestidad de todos los partidos políticos, difundida con el arranque de la lucha despiadada por la sucesión presidencial del año 2006, se creó un vacío de poder, sin liderazgo político claro y firme, que produjo una aguda falta de credibilidad de los ciudadanos en la política y en sus representantes. Ante ello, los medios electrónicos especialmente la televisión, amparados en la ideología de la "libertad de información", ocuparon gradualmente la jefatura ideológica abandonada por los partidos y otros órganos de gobierno que se dedicaron a despedazarse y debilitarse entre sí; y se convirtieron en los nuevos caudillos electrónicos para dirigir a la comunidad nacional hacia la próxima sucesión presidencial.

Así, en el proceso de transición a la democracia y en el preámbulo de la sucesión presidencial de 2006, los canales electrónicos se erigieron en los nuevos barones del poder y a través de los videoescándalos evidenciaron la descomposición que experimentaron todos los partidos políticos en México y el tradicional sistema de representatividad burocrático del país al estar penetrados por una avanzada e incontenible corrupción en todos los niveles de su estructura. El proceso político de la lucha por la sucesión presidencial se desplazó del tradicional ámbito político, para posicionarse en el terreno, las reglas, los tiempos, las formas, los pactos, los lenguajes, los castigos y los intereses de las industrias electrónicas.

Con la transmisión de los videoescándalos, los medios agregaron más estiércol al lodazal político que ya existía en el horizonte nacional y difundieron escándalo tras escándalo para ventilar la descomposición institucional acumulada en la estructura política del país. Dicho deterioro político se reflejó, entre otros, a través de la difusión de la denuncia del Toalla Gate, que reflejó los gastos exorbitantes para equipamiento de la residencia presidencial en los Pinos; el fraude del Pemexgate, que reveló 
el desvio de fondos para la campaña del PRI de Labastida Ochoa a la Presidencia de la República en 2000; los Amigos de Fox, que reveló los apoyos financieros canalizados para la promoción de Vicente Fox Quezada como candidato del PaN a la Presidencia de la República en 2000; el uso de la institución filantrópica Vamos México que enseñó las subvenciones para fortalecer a la primera dama como candidata del PAN a las Presidencia de la República en 2006; el Nico Gate que ventiló los salarios desorbitados del chofer de López Obrador y otros privilegios; las irregularidades en la Lotería Nacional para destinar fondos a la institución Vamos México, etcétera. ${ }^{5}$

Así, ante el déterioro político e institucional del gobierno y de los partidos, los medios operaron tres fuertes estrategias corporativas políticoinformativas para fortalecer su proyecto de dirección y estructura social.

En primer término, debido a la necesidad de obtener recursos en la difícil batalla competitiva por la disputa de los auditorios y sobrevivir ganando más recursos económicos, vía la publicidad, los medios electrónicos convirtieron esta crisis política en un gran reality sbow donde lo que dominó fueron las reglas comunicativas de espectáculo sensacionalista, inmediatista, frívolo, efectivista y light para abrir ante los ojos de la opinión pública las cloacas subterráneas de la descomposición política nacional. ${ }^{6}$ Así, como en

las telenovelas, los medios organizaron el juego de los protagonistas y los segundones. Ponen los reflectores a balconear lo que estaba desconocido o significaba una simple sospecha. Multiplican o disminuyen el potencial de todos los símbolos que están en juego. Lo importante es que no decaiga el interés, que no desfallezca el ánimo de los participantes. Los manejan el escándalo, sus consecuencias, su entorno y su ritmo [González, 2004: 7-A].

En segundo término, considerando que el candidato político más fuerte para la sucesión presidencial de 2006 era Andrés Manuel López Obrador, los medios electrónicos se alinearon con la estrategia preelectoral de la Presidencia de la República para golpear al Jefe de Gobierno del Distrito Federal mediante el proyecto descalificador del videogate. La intención fue clara: no se trató de castigar a los infractores, sino sólo de desprestigiar al principal oponente electoral. ${ }^{7}$

s "Corrupción por televisión", Siempre, México, 17 de marzo del 2004, p. 12.

${ }^{6}$ Sergio Sarmiento, "Reality Shows", Reforma, 4 de marzo del 2004; "Limpiar la guerra sucia", Siempre, México, 7 de marzo del 2004; "Regular la conducta de los medios", Siempre, México, 14 de marzo del 2004; "El peso del escándalo", La Voz de Michoacân, Morelia, Michoacán, México, 9 de abril del 2004; "En la mira los medios de comunicación", Siempre, México, 2 de mayo del 2004, pp. 22 y 23.

7 "Se desató el lodazal político con videos", Ovaciones, México, 4 de marzo del 2004; "La pareja presidencial se sube al videogate", El Financiero, México, 10 de marzo del 2004; "Escándalos y transas. Predominio de las filtraciones, Siempre, México, 14 de marzo del 2004, pp. 14 y 15; "Deterioro de la vida pública", Siempre, México, 4 de abril del 2004. 
Finalmente, en tercer término, los medios electrónicos abandonaron el tradicional diálogo cómplice pactado con el poder público practicado en sexenios anteriores, y apoyados en las libertades de expresión y de información garantizadas por los artículos 6 y 7 constitucionales, actuaron momentáneamente como un contrapeso o poder independiente frente al gobierno y los partidos políticos, y ejercieron su función de fiscalía social exigiendo la rendición de cuentas públicas, la honestidad, la transparencia e intentaron regular el ejercicio de los otros tres poderes republicanos: el poder Ejecutivo, el Legislativo y el Judicial. Los medios se "convirtieron en foro de denuncias públicas para combatir las deficiencias de la administración pública, la corrupción y la incapacidad de los gobernantes" (Scherer, 2004: 23). Sin embargo, esta acción coyuntural no garantiza que posteriormente los medios practiquen la ética, la moral y el combate frontal a la corrupción en otras fases de la evolución social.

De esa forma, mediante la difusión de los videoescándalos se denunció públicamente al senador Jorge Emilio González Martínez, "El Niño Verde" (Presidente del Partido Verde Ecologista), a Gustavo Ponce Meléndez (secretario de Finanzas del Gobierno del Distrito Federal), a Carlos Ahumada Kurtz (empresario, dueño del grupo Quarz y del periódico $E l$ Independiente), a René Bejarano (líder de la Asamblea Legislativa del D.F.), a Carlos Imaz (delegado del PRD en Tlalpan), a Rosario Robles (ex dirigente del Partido de la Revolución Democrática, PRD), a Andrés Manuel López Obrador (Jefe de Gobiernodel Distrito Federal), a Antonio Martínez Ocampo (secretario particular de Carlos Ahumada), etcétera, como miembros o representantes de la cúpula del poder inmersos en una compleja red de corrupción gubernamental, violaciones legales, irresponsabilidades e intrigas para participar en el diseño del maquiavélico proyecto de lucha por el poder político nacional. ${ }^{8}$

8 "Presuntos implicados", Siempre, México, 29 de febrero del 2004, p. 10; "Muerte política", Siempre, México, 29 de febrero del 2004, p. 13; “Segob está involucrada", Milenio, México, 29 de febrero del 2004, p. 12; "Verdes y caníbales", Proceso, núm. 1426, México, 29 de febrero de 2004; p. 34; "Simulación y trampas", Proceso, núm. 1426, México, 29 de febrero del 2004, p. 28; "Cuatro miradas sobre un escándalo no tan leve", Proceso, núm. 1426, México, 29 de febrero del 2004, p. 23-26; "Sacuden videos al GDF", El Universal, 4 de marzo del 2004; "Cimbra video al PRD y GDF", La Jornada, 4 de marzo del 2004; "Pruebas de show y escándalo", Siempre, México, 7 de marzo del 2004; "Estamos en las peores manos", Siempre, México, 7 de marzo del 2004; "Sembrador de corrupción", Proceso, núm. 1427, México, 7 de marzo del 2004; "El escándalo, foco para medios internacionales", $E l$ Independiente, 9 de marzo del 2004; "Juegos sucios", Siempre, México, 7 de marzo del 2004, p. 14; "En las entrañas de Bellagio", Proceso, núm. 1428, México, 14 de marzo del 2004, pp. 24-25; "Profesional de la estafa", Proceso, núm. 1429, México, 21 de marzo del 2004, p. 7; "Los videoescándalos, pugna de grupos políticos en la carrera presidencial: Arzobispo Morales", Excelsior, 23 de marzo del 2004; "Atraería a la PGR el videogate", El Financiero, 23 de marzo del 2004; "Videos vinculan a Fox con el empresario Carlos Ahumada", La Jornada, 24 de marzo del 2004 e "Imágenes después de la fuga", Proceso, núm. 1430, México, 28 de marzo del 2004, p. 27. 
Con la presentación de los videoescándalos se logró un enorme impacto efectivista y persuasivo en la opinión publica, ya que, por una parte, el televidente es un espectador que no pone en duda lo que ve, pues la televisión es víscera, visión, sensación, expectación y no es razón. De aquí, uno de los poderes superiores que ha alcanzado la televisión para poder tocar interiores, convocar conciencias y ganar súbditos. Por otra parte, los espectadores ya no responden a los acontecimientos que visualizan a partir de una cámara, sino que responden a los registros simbólicos de los acontecimientos. Es decir que quien maneja la verdad de los hechos, no son los hechos mismos, sino los mediadores, los que poseen la cámara, ellos son el poder (Scherer, 2004: 23).

Así, entró en acción, una vez más, el fenómeno de la judicialización de la política donde actores públicos irresponsables y sin visión de Estado usaron arbitrariamente asuntos judiciales para difundirlos, confrontarlos, litigar y dirimirlos ante la opinión pública, denostando al adversario con el fin de ganar simpatizantes, en perjuicio de la credibilidad de las instituciones de procuración e impartición de justicia de nuestra República. ${ }^{9}$

Mediante esto el resultado informativo de las industrias mediáticas opera como un eficaz juicio paralelo, donde el derecho a la presunción de inocencia de los individuos cede su garantía ante las condenas que ejecutan los medios antes de investigar y de que intervengan los órganos de justicia especializados en esta delicada responsabilidad. Con ello, el derecho a la inocencia que le corresponde a todo individuo que es una garantía supranacional prevista en el artículo 11, fracción I de la Declaración Universal de los Derechos Humanos que señala que "toda persona acusada de delito tiene derecho a que se presuma su inocencia mientras no se pruebe su culpabilidad, conforme a la ley y en juicio público en el que se le haya asegurado todas las garantias necesarias para su defensa", fue burdamente avasallado y anulado por el resultado efectivista de los medios de información (Villanueva, 2004: 58, 200: 49).

De ese modo, los juicios paralelos operan como pronunciamientos que no se limitan a dar un seguimiento informativo de un hecho noticioso que deviene en caso judicial, sino que de manera implícita o explícita, asumen posturas editoriales en el manejo de la información que prejuzga sobre la inocencia o culpabilidad de alguien, se tenga razón o no. Con ello, se argumenta que los juicios paralelos tienen la bondad de propiciar que se ponga en marcha la maquinaria de procuración de justicia, particularmente en países como México donde no existe un verdadero estado de derecho y, por lo tanto, no se puede confiar en que todos los casos judiciales tomen el cauce que marca la ley (Villanueva, 2004: 8).

9 "Litigar en los medios para ganar simpatizantes", Siempre, núm. 2660, México, 6 de junio del 2004, pp. 36 y 37, y "La Procuraduría General de Justicia, decepcionante papel", Siempre, núm. 2661, México, 13 de junio del 2004, pp. 6 y 7. 
De esa forma, los conductores de televisión o los lectores de noticias se convierten en severos fiscales y jueces que dictan sentencias, sin que se busquen pruebas contundentes que lo confirmen o se dé alternativas de defensa mediática a las personas afectadas y ante los cuales es imposible cualquier apelación (Sarmiento, 2004: 36-37). Así,

hoy en día hasta el menos preparado de los conductores de radio y televisión se erige en nombre de la libertad de prensa en investigador penal, policía judicial, Ministerio Público, juez y verdugo. Ante el viejo sueño social de justicia pronta y expedita, con sentencia inapelable, pues hay que recordar que en el país no se resuelven 95\% de las denuncias; el video clandestino ocupa, por derecho de rating, todas las instancias de la procuración de justicia. En una jornada se descubre, se enjuicia, se procesa y se somete a juicio de esta nueva ley de hierro a todo culpable previo, negociado por los dueños de la televisión [Caballero, 2004: 36, 37].

Son los medios los que desenredan el hilo, los que explican, los que 352 interpretan y los que juzgan. Ellos tienen la varita de la virtud para encantar y desencantar a los personajes, elevar o hundir reputaciones (González, 2004: 7-A).

Esta práctica mediática genera presiones ilegítimas sobre los juzgadores para adaptar sus resoluciones a las expectativas sociales que han formado los medios en la opinión pública sobre un caso determinado, afectando seriamente el principio de un proceso justo e imparcial. Lo que se logra con una irresponsable cobertura mediática es distorsionar la impartición de justicia, presionando a que las informaciones mediáticas se impongan sobre las verdades jurídicas, sean éstas ciertas o no. Aquí es donde vale preguntarse: ¿Es justa la justicia cuando se aparta de la ley para tener como referencia el juicio paralelo de los medios? ¿Qué pasa, entonces, con el derecho fundamental a la presunción de inocencia o el establecido en la Constitución y las leyes que deberían ser la única guía? (Villanueva, 2004: 58, 2000: 49).

Estas presiones mediáticas han provocado en los juzgados que la ley no se aplique con rigor o a raja tabla como lo exige cualquier estado de derecho, sino que, en algunos casos, se llegue al extremo de ejercer la justicia hasta que pasan los tiempos políticos conflictivos para evitar la politización de los casos judiciales. ${ }^{10}$ De esta forma, los "videojuicios" sumarios son un indicador que muestra la fuerte descomposición de nuestro régimen de justicia, del sistema ético y del sistema político nacional por la que atraviesa el frágil proyecto de construcción de la democracia nacional. Con su existencia se debilita a las instituciones del poder Judicial que son las únicas que pueden ejercer un verdadero cambio en el ejercicio del sistema de procuración de justicia en México.

10 "Litigar en los medios para ganar simpatizantes", Siempre, núm. 2660, México, 6 de junio del 2004, pp. 36 y 37 
Sin embargo, ante esta situación no se considera que el que "los medios de comunicación se conviertan en poder Judicial, en poder político o en última norma ética y social, y efectúen un linchamiento mediático desde las pantallas de televisión y desde las páginas de los periódicos, también es un hecho ilícito: destruir y difamar también es corrupción. Si el abandono de los valores éticos produce abuso y corrupción, epor qué entonces sólo se practican los valores económicos y no los valores éticos: justicia, igualdad y derechos humanos y culturales?"(Maza, 2004: 23-24) El respeto al derecho de la presunción a la inocencia, no sólo es un deber jurídico de los medios, sino una responsabilidad deontológica para hacer una comunicación sana y creíble.

Ante los vacíos de poder que se dieron por la incapacidad de los agentes políticos para resolver los problemas con honestidad y profesionalismo, los medios ocuparon estos espacios con sus mensajes y se convirtieron en un poder que definió la agenda de la discusión política del país por encima de todos los poderes del Estado, de la Constitución y de la sociedad. Se posicionaron como un poder ilimitado, el poder del poder, sin ley, ni orden, sin normas mínimas de contención a favor de los derechos informativos de la comunidad, y respondiendo sólo a las indicaciones de la autorregulación (Caballero, 2004: 36).

Con la difusión de los videoescándalos a todo color, en tercera dimensión, con sonido estereofónico y con gran dinamismo dramático, los auditorios vieron desfilar recurrentemente en las pantallas caseras la imparable corrupción, la impunidad, el cinismo, el abuso, la parálisis de la justicia, la pasividad de los gobernantes, la falta del estado de derecho y la ausencia profunda de dirección nacional. Con ello, la población acumuló silenciosamente en su interior un enorme desencanto, frustración, desánimo, irritación, apatía, impotencia, coraje e incredulidad que ha creado un clima de profundo malestar colectivo, equivalente a una gran bomba social con mecha cada vez más corta. En pocas palabras, con la difusión de las imágenes y sonidos de los medios observamos cotidianamente un país que se descompone, se deshace y se derrumba ante nuestras narices, sin la existencia de un Estado viril fuerte que le dé rumbo firme hacia la sobrevivencia colectiva, y que, cada vez más, impone las leyes del darwinismo social con la depredación del más fuerte sobre el más débil.

De esta manera, mientras no existieron recursos económicos para comprar medicinas, para construir carreteras, para crear escuelas, para generar empleos, para abrir proyectos de la juventud, para generar alimentos, para apoyo a los ancianos, para la reforestación del país, para pagar las pensiones de los jubilados, para combatir la creciente delincuencia, para renovar la infraestructura médica de salud nacional, etcétera; los medios cotidianamente difundieron ante nuestros ojos las imágenes del tesorero del Gobierno del Distrito Federal apostando los recursos públicos en las 
Vegas, los diputados cobrando altas cifras durmiéndose en sus curules, los embajadores comprando colchones y mensajes de casa lujosísimos en el extranjero, los administradores del gobierno recibiendo bolsas de papel llenas de dólares, los funcionarios públicos pagando sueldos altísimos a sus chóferes, los jefes de delegación aceptando cohecho a cambio de asegurar contratos de construcción, los legisladores perseguidos por la justicia debido a su conducta corrupta, los secretarios de Estado negociando con todas las autoridades para evitar que se sepa la verdad, el narcotráfico aliado con los intereses de los gobernadores, el gobierno mexicano rompiendo relaciones diplomáticas con el gobierno de Cuba sin dar demostraciones contundentes de razón, etcétera.

Por otra parte, mientras todos los años el gobierno federal aplica una reforma fiscal más agresiva contra el erario personal de los ciudadanos para que paguen más impuestos, los medios nos enseñan con transparencia cotidiana como con nuestros recursos económicos financiamos los sueldos elevados del personal privado de los funcionarios de gobierno, los reventones del "Niño Verde" en Europa y otras partes del mundo, el aprovechamiento del tiempo público de un legislador del Partido Verde Ecologista para participar en Big Brother VP, la acumulación de cuentas en dólares de los líderes de los partidos en los bancos extranjeros, el uso excesivo de los teléfonos celulares por los representantes públicos, los fraudes del Partido de la Sociedad Nacionalista con recursos públicos, etcétera.

Al observar, vía los videoescándalos que cada semana un nuevo hecho de corrupción substituye al anterior y con ello, que la descomposición y la injusticia penetraron irrefrenablemente todos los rincones de la esfera pública, corroyendo todos los ámbitos de la vida nacional, se empezó a agotar la capacidad de asombro de la ciudadanía. Al ahogarnos de verdades escandalosas, lo único que quedó es el estado anímico mediático de sorpresa, desencanto, frustración, desesperanza y coraje que, cada día, anuncian los canales de información. El saldo que arroja la creación de esta atmósfera mediática es una fuerte erosión de las instituciones de la República, la crisis del poder Ejecutivo, el descrédito del Congreso, la pérdida de credibilidad en los partidos políticos, la desilusión en el sistema establecido, la desconfianza en lo público, la incredulidad en el gobierno, la crisis de obediencia colectiva en los líderes tradicionales, la gran inclinación al abstencionismo en los próximos periodos electorales y la generación de las bases psico-anímicas para el surgimiento de la anarquía y el desbordamiento nacional.

En este sentido,

la sobrecarga de información sucia que difunden los canales de difusión está produciendo una peligrosa hipertensión en el público que tarde o temprano se va a manifestar en la no participación en las urnas. Los medios de comunicación 
deben estar muy alertas, pues en el juego de ganar más raiting y dinero con la última exclusiva grabada por las cámaras clandestinas, pueden arrinconar y poner al borde del abismo la democracia adolescente que ha conseguido alcanzar la sociedad mexicana con muchísimos esfuerzos y dolor. Como sucede con el abuso de la energía eléctrica, la sobrecarga puede provocar un corto circuito o la explosión de algún transformador de energía. En este caso, el corto circuito sería el colapso de la idea de democracia en la conciencia de las personas, y la explosión del transformador, el estallido social [Septién, 2004: 64].

La culpa no la tienen ni los medios, ni la sociedad, sino los políticos corruptos que se han vinculado desde hace décadas con los dueños del dinero para repartirse el país como un botín nacional, a costa del subdesarrollo y la desesperanza de la mayoría de los habitantes. El problema no es que los políticos mexicanos se hayan vuelto súbitamente corruptos. Los mexicanos siempre hemos sabido que nuestros políticos son corruptos. La diferencia es que ahora vemos a todo color, en cadena nacional, sus trampas, engaños, cinismos, robos, impunidades y abusos, con lujo de detalle en las pantallas de televisión (Mendoza, 2004: 43). En otras palabras, para la clase política el conflicto no está en que exista corrupción, pues ésta siempre ha existido, sino en que ahora todos los días se sepa públicamente y su difusión no se pueda controlar.

De esta forma, si con los profundos reacomodos del poder que se generaron con la transición a la democracia el nivel de confianza en las instituciones públicas del país se deterioró seriamente, ahora con la presencia constante de las escenas de la descomposición del sistema político en los medios de difusión, la credibilidad en lo público y en la transición a la democracia quedó profundamente vulnerada. Al denostar y acabar de desprestigiar a la clase política por sus grandes errores, el camino quedó abierto para conseguir su sustitución por la clase empresarial y su proyecto globalizador de crecimiento excluyente (Maza, 2004: 24).

Frente a las enormes contradicciones y tensiones acumuladas en el país, entre gobierno y sociedad, estamos en un periodo de profundo riesgo social insospechado, pues se han despertado enormes energías sociales de incalculable impacto para la estabilidad del sistema que se requieren canalizar institucional y civilizadamente para evitar la emergencia de la anarquía social.

Así, al romperse las viejas alianzas políticas entre concesionarios y clase gobernante que blindaron eficientemente con la deformación informativa la estructura de abuso, desigualdad y corrupción histórica del viejo sistema político nacional durante 70 años, ahora los medios presentan con transparencia diversos indicadores de la descomposición nacional. Las preguntas ahora son: ¿Si con esta difusión de hechos, los propietarios de los medios se han convertido de la noche a la mañana en los paladines de la ética, de la honestidad y de la práctica del derecho a la información o simplemente 
están pactando nuevas alianza para blindar otro proyecto político que los proteja? ¿Si con esta intervención los concesionarios de medios pretenden promover imparcialmente el derecho a la información o simplemente han acumulado más cuotas de poder para subordinar con mayor fuerza al Estado y a la sociedad e imponer su proyecto darwinista de autorregulación comunicativa?

En este contexto político-tecnológico los medios controlan, cada vez más, al Estado, a los partidos políticos, a los organismos civiles y a la sociedad; la pregunta ahora es ¿Quién controla a los medios de información? ¿Dónde está el contrapoder legal que equilibre las sinrazones de este engendro del autoritarismo? ¿Quién se atreve siquiera a nombrarlo si todos viven de él, para él y desde él? (Caballero, 2004: 36)

Si los concesionarios de los medios están realmente comprometidos en la lucha contra la corrupción y en preservar la legalidad, deben aceptar la reforma profunda del marco jurídico de los medios, especialmente de sus aspectos ciudadanos, que tiene décadas congelada por estar saboteada por ellos mismos. El buen juez por su casa empieza. ${ }^{11}$

Al iniciar el siglo XxI políticamente es insostenible que se vuelva a repetir la historia tradicional en materia de comunicación colectiva de "no encontrarle la cuadratura al circulo". Por ello, después del despertar democrático de la sociedad mexicana el 2 de julio de 2000, ahora el Congreso de la Unión tiene la enorme responsabilidad histórica de ejercer su función de poder Legislativo demostrando contundentemente que sí se puede construir la otra historia democrática de la comunicación nacional. Ante los signos de cambio urgente y desesperado del México Profundo que se manifestaron con el levantamiento de los machetes campesinos de Atenco, la toma rural de la carretera federal a Cuernavaca, las decenas de manifestaciones diarias en las calles y avenidas de las principales ciudades de la República, la aplicación popular de la justicia por propia mano en Milpa Alta, el asalto violento de los productores agropecuarios al Congreso de la Unión en 2003, la organización nacional de los campesinos para bloquear el Tratado de Libre Comercio en el rubro de importación de alimentos, la Mega Manifestación de protesta de 2003 en contra de la privatización de la energía eléctrica, ${ }^{12}$ la crisis de corrupción y dirección de todos los partidos políticos que se evidenciaron con los videoescándalos y otras filtraciones noticiosas, el desprestigio creciente de la Cámara de Diputados como órgano de representación ciudadana, la

\footnotetext{
"Carlos Gómez Valero, "El video escándalo, golpe a la transición", documento inédito, México, p. 3.

12 "Tomarán el Zócalo por cuatro frentes", El Independiente, 26 de noviembre del 2003; Todo listo para la mega marcha, Milenio Diario, 26 de noviembre del 2003
} 
Mega Marcha Pacífica por la Justicia en 22 ciudades de la República ${ }^{13}$ y el resurgimiento de los movimientos guerrilleros en diversas zonas del país, la comunidad mexicana espera la firme respuesta del poder Legislativo en materia de comunicación colectiva para evitar estos desbordamientos sociales que van en acelerado aumento y lograr la transición pacífica a la democracia nacional.

Comunicativamente, la nación ya no aguanta más. Hoy, se requiere la urgente creación de un nuevo proyecto de comunicación colectiva que dé salidas comunicativas incluyentes a la sociedad mexicana. De lo contrario, de nuevo surgirá el proyecto de intervención y comunicación violenta del México Bronco que ha ensangrentado diversos periodos de la historia nacional.

De aquí, la importancia central de efectuar una profunda reforma del Estado en materia de comunicación y cultura colectiva que permita que el funcionamiento público de las industrias culturales se encuentre ética y jurídicamente orientado y supervisado por el Estado y la sociedad civil mexicana, y no sólo por las caprichosas dinámicas de la Mano Invisible del mercado autorregulado que ha introducido la globalización contemporánea.

\section{Documentación consultada}

\section{Libros y revistas}

Caballero Pedraza, Virgilio Dante (2004), "Los medios en el lodazal: ¿El poder del poder?", en Los Periodistas, Fraternidad de Reporteros de México, A.C, México, abril.

Corral Jurado, Javier (2003), "Mediocracia sin mediaciones", en El Universal, Columna Rotafolio, 20 de enero.

(2002), "Pluralidad, acceso y competencia", V Conferencia Internacional: Los medios electrónicos en el marco de la Reforma del Estado en México, VIII Legislatura, Cámara de Diputados/H. Congreso de la Unión/Universidad Iberoamericana/Fundación Konrad Adenauer-Stiffung/ Organización de las Naciones Unidas para la Educación la Ciencia y la Cultura (UNESCO)/Universidad Autónoma Metropolitana/Comisión de Radio, Televisión y Cinematografía (RTC), Salón Verde, Palacio Legislativo, México, 27 a 29 de mayo, disponible en http://www.cddhcu.gob.mx/servddd/versest/2ano/comisiones/rtc-3.htm. Gauraleri, Gianpiero (1981), La galaxia de McLuban, ATE, España.

\footnotetext{
13 "Se desborda la exigencia social a las autoridades", Excelsior, 28 de junio del 2004; "Sacuden al país", El Universal, 28 de junio del 2004; "Unidos contra la violencia", El Sol de México, 28 de junio del 2004; "La multitud arrebató la marcha a los organizadores", La Jornada, 28 de junio del 2004 y "Temblor social, solidaridad como en el 85", Diario Monitor, 28 de junio del 2004.
} 
Gómez Valero, Carlos, "El video escándalo, golpe a la transición", documento inédito, México.

Labra, Armando (1989), "Prólogo", en La legislación mexicana en radio y televisión, $1^{\text {a }}$. reimp. (Colección Ensayos), UAM- Xochimilco, México.

Maza, Enrique (2004), "Linchamiento mediático", en Proceso, núm.. 1429, México, 21 de marzo.

McLuhan, Marshall (1979), La comprensión de los medios como las extensiones del bombre, Diana, México.

McBride, Sean (1985), Un sólo mundo. Voces mültiples comunicación e información en nuestro tiempo, FCE, México.

Mendoza, Enrique (2004), "Videoescándalos. Regular la conducta de los medios", Siempre, 14 de marzo.

Sarmiento, Sergio (2004), "Corrupción por televisión", en Siempre, 7 de marzo.

- (2004), "Reality shows", en Reforma, 4 de marzo.

Scherer Ibarra, María (2004), "Telearquía", en Proceso, núm. 1427, México, 27 de marzo.

Septién, Jaime (2004), "El video lodazal", en Siempre, México, 14 de marzo.

Villanueva, Ernesto (2000), "Medios y presunción de inocencia", Proceso, núm. 1213, México, 30 de enero.

(2004), "Medios, juicios paralelos y poder", en Proceso, núm. 1433, México, 18 de abril.

- (2004), "Medios, transparencia y democracia", en Proceso, núm. 1427, México, 7 de marzo.

\section{Hemerografia}

"Atraería a la PGR el videogate", El Financiero, 23 de marzo de 2004.

"Cimbra video al PRD y GDF", La Jornada, 4 de marzo de 2004.

"Corrupción por televisión", Siempre, México, , 17 de marzo de 2004.

" Cuatro miradas sobre un escándalo no tan leve", Proceso, núm. 1426, México, 29 de febrero de 2004 .

"Deterioro de la vida pública", Siempre, México, 4 de abril de 2004.

"El escándalo, foco para medios internacionales", El Independiente, 9 de marzo de 2004 .

"En la mira los medios de comunicación”, Siempre, México , 2 de mayo de 2004. "En las entrañas de Bellagio", Proceso, núm. 1428, México, 14 de marzo de 2004.

"Escándalos y transas. Predominio de las filtraciones", Siempre, México, 14 de marzo de 2004.

"Estamos en las peores manos", Siempre, México, 7 de marzo del 2000.

"Formaliza Castañeda precandidatura al 2006", Reforma 26 de marzo de 2004.

"Los escándalos y los medios. Relaciones peligrosas", Edmundo González Llaca (2004), Excelsior, 13 de mayo.

"Imágenes después de la fuga", Proceso, núm. 1430, México, 28 de marzo de 2004. "Juegos sucios", Siempre, México, 7 de marzo de 2004.

"La multitud arrebató la marcha a los organizadores", La Jornada, 28 de junio de 2004.

"La pareja presidencial se sube al videogate", El Financiero, México, 10 de marzo de 2004 . 
"La Procuraduría General de Justicia, decepcionante papel", Siempre, núm. 2661, México, 13 de junio de 2004.

"Limpiar la guerra sucia", Siempre, México, 7 de marzo de 2004.

"Litigar el los medios para ganar simpatizantes", Siempre, núm. 2660, México, 6 de junio de 2004.

"Los videoescándalos, pugna de grupos políticos en la carrera presidencial: Arzobispo Morales", Excelsior, 23 de marzo de 2004.

"Minipartidos a la caza del güero", Milenio, 23 de febrero de 2004.

"Muerte política", Siempre, México, 29 de febrero de 2004.

"Presuntos implicados", Siempre, México, 29 de febrero de 2004.

"Profesional de la estafa", Proceso, núm. 1429, México, 21 de marzo de 2004.

"Pruebas de Show y escándalo", Siempre, México, 7 de marzo de 2004.

"Regular la conducta de los medios", Siempre, México, 14 de marzo de 2004.

"Sacuden al país", El Universal, 28 de junio de 2004.

-"Sacuden videos al GDF", El Universal, 4 de marzo de 2004.

"Se desató el lodazal político con videos", Ovaciones, México, 4 de marzo de 2004.

"Se desborda la exigencia social a las autoridades", Excelsior, 28 de junio de 2004.

"Sembrador de corrupción", Proceso, núm. 1427, México, 7 de marzo de 2004.

"Simulación y trampas", Proceso, núm. 1426, México, 29 de febrero de 2004.

"Temblor social, solidaridad como en el 85", Diario Monitor, 28 de junio de 2004.

"Todo el poder", Proceso, núm. 1433, México, 18 de abril de 2004.

"Todo listo para la mega marcha", Milenio Diario, 26 de noviembre del 2003.

"Tomarán el Zócalo por cuatro frentes", El Independiente, 26 de noviembre del 2003

"Verdes y caníbales", Proceso, núm. 1426, México, 29 de febrero de 2004.

"Videos vinculan a Fox con el empresario Carlos Ahumada", La Jornada, 24 de marzo de 2004.

"Unidos contra la violencia”, El Sol de Méxicó, 28 de junio de 2004. 